Original Article

\title{
INCIDENCE OF PRENATAL AND POSTNATAL RISK FACTORS FOR CHILDHOOD ASTHMA
}

\author{
Milica Jakovljević ${ }^{1}$, Dragana Mitrović², Snežana Živanović ${ }^{1,3}$ \\ ${ }^{1}$ Faculty of Medicine, University of Niš, Niš, Serbia \\ ${ }^{2}$ Health Center Knjaževac, Serbia \\ ${ }^{3}$ Pediatric Clinic, Clinical Center Niš, Serbia
}

\begin{abstract}
Asthma is one of the most frequent chronic diseases of childhood. Its etiology is not fully understood and risk factors for its development are numerous. The aim of this study was to determine the incidence of prenatal and postnatal risk factors in children suffering from asthma. The study was conducted on a sample of 100 patients with a diagnosis of asthma according to Global Initiative for Asthma guidelines. The data was collected using a questionnaire. We have considered prenatal (smoking during pregnancy, hormone and antibiotic therapy, the use of acetaminophen and dietary supplements, maternal blood sugar level, the term of delivery and the method of childbirth) and postnatal risk factors (oxygen and antibiotic therapy during the first year of life, immunization status during the first 6 months of life and presence of the older sibling in the family). In our study group, the most common prenatal risk factors related to asthma were: smoking during pregnancy, hormone therapy, the use of the dietary supplements and delivery via Caesarean section, while the most frequently found postnatal risk factors were: antibiotic therapy during the first year of life and the presence of older child in the family.
\end{abstract}

Key words: asthma, prenatal risk factors, postnatal risk factors.

\section{Introduction}

Asthma is one of the most frequent chronic diseases of childhood. According to GINA (Global Initiative for Asthma) guidelines, it affects around 300 million individuals [1]. The prevalence of asthma in children aged $13-14$ years is $1.5-15.6 \%$, thus making it a global health problem [1]. It is believed that chronic inflammation and structural changes in respiratory tract lead to reversible airflow obstruction and bronchial hyper-reactivity [2]. Its etiology is not fully understood. It is believed that both genetics and environmental factors play a role in its etiology [3]. According to literature data, the most important prenatal risk factors for childhood asthma are: smoking during pregnancy, maternal diet, low birth weight, use of antibiotics during pregnancy and delivery via cesarean section, while the most important postnatal risk factors are allergic sensitization, environmental tobacco smoke exposure, exposure to animals, breastfeeding, decreased lung function during infancy, family size and structure, socio-economic status, antibiotics use and gender [3,4]. Studies performed among twins showed that genetic factors have a significant role in the development of asthma [5].

Correspondence to: Milica Jakovljević, M.D

Faculty of Medicine, 81 Zoran Đinđić Blvd., 18000 Niš, Serbia

Phone: +381638727136

E-mail: milicajakovljevic@mail.com

Received February $1^{\text {st }}, 2018$, Accepted December $20^{\text {th }}, 2018$

\section{Objective}

The aim of this investigation was to determine the frequency of prenatal and postnatal risk factors in children with asthma.

\section{Material and Methods}

The study was conducted at the Pulmology and Allergology Department of Nis Clinical Center Pediatric Clinic, from November 2016 to March 2017, on a sample of 100 patients with a diagnosis of asthma according to GINA (Global Initiative for Asthma) guidelines. In our study group, male to female ratio was 61:39 $(n=61$; $\mathrm{n}=39$ ). The youngest patient included in the study was 19 months old and the eldest 17 years and 6 months. In 41 children (41\%), the first symptoms of asthma occurred before 3 years of age. The data was collected from children's parents by using a questionnaire. Prenatal risk factors included: smoking during pregnancy with the number of cigarettes smoked per day, hormone and antibiotic therapy as well as the use of acetaminophen and dietary supplements, high maternal blood sugar level. The data regarding the delivery term and method have been also included in the questionnaire. Postnatal risk factors were: oxygen and antibiotic therapy during the first year of life, incomplete immunization in the first 6 months of life and the presence of the older sibling in the family. 


\section{Results}

An analysis of prenatal risk factors showed that mothers were active smokers during pregnancy in $18 \%$ of all cases (number of cigarettes $\leq 5$ per day in $12 \%$ and $6 \%>$ 5 cigarettes). Hormone therapy was used in $26 \%$ of the pregnancies $(n=26)$, especially during the second and third trimester. Progesterone medications were most commonly used $(\mathrm{n}=10 ; 38 \%)$. Eleven mothers $(11 \%)$ received antibiotics during pregnancy. $\beta$-lactam antibiotics were most commonly used $(n=6 ; 55 \%)$, followed by cephalosporins $(\mathrm{n}=2 ; 18 \%)$ and macrolides $(\mathrm{n}=1$; $8 \%$ ). Antibiotics were used during different periods of pregnancy. Acetaminophen was used during $3 \%$ of pregnancies, especially during the last trimester. Dietary supplements were used in $57 \%$ of cases. Vitamin complex $(n=24 ; 42.1 \%)$ and folic acid $(n=14 ; 24.5 \%)$ were most frequent. In $7 \%$ of cases $(n=7)$ glucose intolerance or gestational diabetes was found. $95 \%(n=95)$ had full term delivery. Caesarean section was found in $23 \%$ of all cases $(n=23)$. An analysis of postnatal risk factors showed that $26 \%$ of children $(n=26)$ had oxygen and 61 children $(61 \%)$ antibiotic therapy during the first year of life. Immunization was completed according to immunization schedule in $87 \%$ of cases $(n=87)$. Forty five percent of children $(n=45)$ had older sibling.

The results are shown in Tables 1, 2 and 3.

Table 1 Prenatal risk factors in asthmatic children

\begin{tabular}{lcc}
\hline & $\begin{array}{c}\text { Present } \\
(\%)\end{array}$ & $\begin{array}{c}\text { Not } \\
\text { present } \\
(\%)\end{array}$ \\
\hline Mother as active smoker & 18 & 82 \\
Glucose intolerance or gestational diabetes & 7 & 93 \\
Antibiotic therapy & 11 & 89 \\
Hormone therapy & 26 & 74 \\
Acetaminophen & 3 & 97 \\
Dietary supplements & 57 & 43 \\
Full-term delivery & 95 & 5 \\
Caesarean section & 23 & 77 \\
The number of cigarettes per day & $\leq 5$ & $>5$ \\
& 12 & 6 \\
\hline
\end{tabular}

\section{Discussion}

In the study group, $18 \%$ of the mothers were active smokers during the pregnancy. In the literature, the incidence of mothers who smoked during pregnancy is up to $40 \%$ [6]. Six mothers $(30 \%)$ smoked more than 5 cigarettes a day. Studies have shown that nicotine passes through the placenta and affects the development of fetal lungs [7,8], thus increasing the risk of asthma onset in childhood [4,9]. Smoking during pregnancy was associated with an increased risk for wheezing before the second year by $40 \%$ and between 5 and 18 years of age by $52 \%$, while the children of mothers who smoked more than 10 cigarettes during pregnancy had a $35 \%$ increased risk of asthma before age of seven $[10,11]$. Eleven mothers received antibiotic therapy during pregnancy.

According to the data from literature, $35 \%$ of mothers whose children had asthma used antibiotic therapy during pregnancy [12]. The connection between antibiotics use during pregnancy and the increased risk of asthma onset is controversial. Some studies have shown increased risk of asthma, while in other, authors have come to the conclusion that the use of antibiotics is in fact an indicator of the mother's tendency towards inflammatory reactions and infections and not a risk factor by itself [13-17]. According to the "hygiene hypothesis" reduced exposure to microorganisms can lead to a change in immune system and predispose the individual to atopic reactions [18]. The use of antibiotics in pregnancy may cause a change in the mother's microbiota and predisposes the child to atopic reactions, particularly by stimulating the Th2 cell response [19,20]. In pregnant mothers $\beta$-lactam antibiotics were most commonly used ( $\mathrm{n}=6 ; 55 \%)$, which is in accordance to literature data. The use of penicillin, especially during the first trimester of pregnancy, significantly increases the risk of asthma in childhood [21]. In our study, antibiotics have been administered during all trimesters of pregnancy. The use of antibiotics during the second and third trimesters proved to be a risk factor for the onset of asthma in childhood [22].

Table 2 Representation of prenatal risk factors during gestation period in asthmatic children (\%)

\begin{tabular}{lcccccc}
\hline & $\begin{array}{c}\text { First } \\
\text { trimester }\end{array}$ & $\begin{array}{c}\text { Second } \\
\text { trimester }\end{array}$ & $\begin{array}{c}\text { Third } \\
\text { trimester }\end{array}$ & $\begin{array}{c}\text { First and second } \\
\text { trimester }\end{array}$ & $\begin{array}{c}\text { Second and third } \\
\text { trimester }\end{array}$ & All 3 trimesters \\
\hline Antibiotic therapy & 3 & 4 & 3 & & & \\
Hormone therapy & 3 & & 2 & 2 & 11 & 8 \\
Acetaminophen & & & 3 & & & \\
\hline
\end{tabular}

Table 3 Postnatal risk factors in asthmatic children

\begin{tabular}{lcc}
\hline & $\begin{array}{c}\text { Present } \\
(\%)\end{array}$ & $\begin{array}{c}\text { Not } \\
\text { present } \\
(\%)\end{array}$ \\
\hline Antibiotic therapy & 61 & 39 \\
Oxygen therapy & 26 & 74 \\
Immunization completed & 87 & 13 \\
The presence of older sibling in family & 45 & 55 \\
\hline
\end{tabular}

In our study group, Acetaminophen was used in only $3 \%$ of all cases. Numerous studies have linked the prenatal use of Acetaminophen with an increased risk of childhood asthma, but it was not possible to exclude that these were just confounding factors [23,24].

The use of dietary supplements, especially folic acid, which reduces the risk of neural tube defects, has been reported in more than half of all cases. The data showing that the use of folate increases the possibility of 
developing asthma in childhood are controversial studies are few and some of them show that there is no link between prenatal use of folate and asthma while others show that folate increases the risk of asthma $[25,26]$.

In $7 \%$ of cases $(n=7)$ the glucose intolerance or gestational diabetes were present. The incidence of these maternal risk factors in the literature is $2 \%$ and children whose mothers were suffering from diabetes and asthma both had a 11.3 times greater risk for developing asthma $[6,27]$.

The full-term delivery was present in $95 \%(\mathrm{n}=95)$ and Caesarean section in $23 \%$ of all cases $(n=23)$. According to data from literature, Caesarean section is considered a risk factor for the onset of asthma in childhood $[3,4]$.

An analysis of postnatal risk factors found that $26 \%$ of children $(n=26)$ had oxygen and 61 children $(61 \%)$ antibiotic therapy during first year of life. It is believed that the use of mechanical ventilation and oxygen causes barotrauma and exposes the lungs to oxygen free radicals and contributes to the development of bronchopulmonary dysplasia in premature babies thus increasing the incidence of asthma and bronchial hyperreactivity [28]. Broad spectrum antibiotics, especially when administered to children with no genetic predisposition for asthma, increase the risk of developing childhood asthma [29-31]. Immunization was completed according to immunization schedule in $87 \%$ of cases ( $\mathrm{n}$ = 87). The KOALA study (Child, parents and health: lifestyle and genetic constitution study) showed that there was no statistically significant difference in the

\section{References}

1. http://ginasthma.org/2017-online-appendix-global-strategy-forasthma-management-and-prevention/

2. Britt RD, Faksh A, Vogel E, Martin RJ, Pabelick CM, Prakash YS. Perinatal factors in neonatal and pediatric lung diseases. Expert Rev Resp Med 2013; 7:515-531.

3. Subbarao P, Mandhane PJ, Sears MR. Asthma: epidemiology, etiology and risk factors. CMAJ 2009; 181:E181-E190.

4. Davidson R, Roberts SE, Wotton CJ, Goldcre MJ. Influence of maternal and perinatal factors on subsequent hospitalisation for asthma in children: evidence from the Oxford record linkage study. BMC Pulm Med 2010; 10:14

5. Willemsen G, van Beijsterveldt TC, van Baal CG, Postma D, Boomsma DI. Heritability of self-reported asthma and allergy: a study in adult Dutch twins, siblings and parents. Twin Res Hum Genet 2008; 11:132-142.

6. Nepomnyaschy L, Reichman NE. Low Birthweight and Asthma Among Young Urban Children. Am J Public Health 2006; 96:1605-1610.

7. Wu FY, Chiu HT, Wu HD, Lin CJ, Lai JS, Kuo HW. Comparison of urinary and plasma cotinine levels during the three trimesters of pregnancy. Paediatr Perinat Epidemiol 2008; 22:296-301

8. Lødrup Carlsen KC, Jaakkola JJ, Nafstad P, Carlsen KH. In utero exposure to cigarette smoking influences lung function at birth. Eur Respir J 1997; 10:1774-1779.

9. Metsälä J, Kilkkinen A, Kaila M, Tapanainen H, Klaukka T, Gissier M, Virtanen SM: Perinatal factors and the risk of asthma in childhood - A population-based register study in Finland. Am J Epidemiol 2008; 168:170-178. incidence of asthma between immunized and non-immunized children [31]. Forty five percent of children (n $=45$ ) had older sibling, which is in accordance with the literature data [4].

The limitation of our study is a relatively small and heterogeneous sample in terms of age (the age ranging from 19 months to 17 years and 6 months) as well as the fact that the data were obtained from the parents and not from the medical records and as such are susceptible to memory bias. More detailed research is necessary due to possibility of one risk factor influencing another and the possible presence of confounding factors.

\section{Conclusion}

In our study group, the most common prenatal risk factors related to asthma were: smoking during pregnancy, hormone therapy, the use of the dietary supplements and delivery via Caesarean section, while the most frequently found postnatal risk factors were: antibiotic therapy during the first year of life and the presence of older child in the family.

Risk factors during pregnancy can affect the occurrence of asthma in children by epigenetic modifications of the genome, whereas postnatal risk factors affect early onset and more severe forms of asthma. Taking into account that the incidence of asthma is rising and that it is an etiologically heterogeneous, chronic disease affecting the health and quality of life, it is important to identify and minimize risk factors as much as possible.

10. Burke H, Leonardi J, Hashim A, Pine-Abata H, Chen Y, Cook DG, Britton JR, McKeever TM. Prenatal and Passive Smoke Exposure and Incidence of Asthma and Wheeze: Systematic Review and Meta-analysis. Pediatrics 2012; 129:735-744.

11. Jaakkola JJK, Gissler M: Maternal smoking in pregnancy, fetal development, and childhood asthma. Am J Public Health 2004; 94:136-140.

12. Lapin B, Piorkoski J, Ownby D, Freels S, Chavez N, Hernandez E, Wagner-Cassanova C, Pelzel D, Vergara C, Persky V. The Relationship between Prenatal Antibiotic Use and Asthma in At-Risk Children. Ann Allergy Asthma Immunol 2015; 114:203-207.

13. Metsälä J, Lundqvist A, Virta LJ, Kaila M, Gissler M, Virtanen SM. Prenatal and post-natal exposure to antibiotics and risk of asthma in childhood. Clin Exp Allergy 2015; 45:137-145.

14. Stensballe LG, Simonsen J, Jensen SM, Bønnelykke K, Bisgaard H. Use of antibiotics during pregnancy increases the risk of asthma in early childhood. J Pediatr 2013; 162:832-838.

15. Örtqvist AK, Lundholm C, Kieler H, Ludvigsson JF, Fall T, Ye $\mathrm{W}$, et al. Antibiotics in fetal and early life and subsequent childhood asthma: nationwide population based study with sibling analysis. BMJ 2014;349:g7395.

16. Popovic M, Rusconi F, Zugna D, Galassi C, Merletti F, Migliore E, Trevisan M, Nannelli T, Gagliardi L, Richiardi L. Prenatal exposure to antibiotics and wheezing in infancy: a birth cohort study. Eur Respir J 2016; 47:810-817.

17. Stokholm J, Sevelsted A, Bønnelykke K, Bisgaard H. Maternal propensity for infections and risk of childhood asthma: a registrybased cohort study. Lancet Resp Med. 2014; 2:631-637. 
18. Renz H, Blumer N, Virna S, Sel S, Garn H. The immunological basis of the hygiene hypothesis. Chem Immun Allergy 2006; 91:30-48.

19. Lange NE, Celedon JC, Forno E, et al. Maternal intestinal flora and wheeze in early childhood. Clin Exp Allergy 2012; 42:901-908.

20. Stokholm J, Schjørring S, Eskildsen CE, Pedersen L, Bischoff AL, Følsgaard N, et al. Antibiotic use during pregnancy alters the commensal vaginal microbiota. Clin Microbiol Infect 2014; 20:629-635.

21. Chu S, Yu H, Chen Y, Chen Q, Wang B, Zhang J. Periconceptional and Gestational Exposure to Antibiotics and Childhood Asthma. PloS One. 2015; 10:e0140443.

22. Zhao D, Su H, Cheng J, Wang X, Xie M, Li K, Wen L, Yang $H$. Prenatal antibiotic use and risk of childhood wheeze/asthma: A meta-analysis. Pediatr Allergy Immunol 2015; 26:56-64.

23. Shaheen SO, Newson RB, Sherriff A, et al. Paracetamol use in pregnancy and wheezing in early childhood. Thorax. 2002; 57:958-963

24. Andersen AB, Farkas DK, Mehnert F, Ehrenstein V, Erichsen R. Use of prescription paracetamol during pregnancy and risk of asthma in children: a population-based Danish cohort study. Clin Epidemiol 2012; 4:33-40.
25. Crider KS, Cordero AM, Qi YP, Mulinare J, Downling NF, Berry RJ. Prenatal folic acid and risk of asthma in children: a systematic review and meta-analysis. Am J Clin Nutr 2013; 98:1272-1281.

26. Veeranki SP, Gebretsadik T, Mitchel EF, Tylavsky FA, Hartert TV, Cooper WO, Dupont WD, Dorris SL, Hartman TJ, Carroll KN. Maternal Folic Acid Supplementation During Pregnancy and Early Childhood Asthma. Epidemiology 2015; 26:934-941.

27. Azad MB Becker AB, Kozyrskyj AL. Association of maternal diabetes and child asthma. Pediatr Pulmol 2013; 48: 545-552.

28. Alshehri MA, Almegamesi TM, Alfrayh AS. Predictors of short-term hospital readmissions of asthmatic children. J Family Community Med 2005; 12:11-17.

29. Risnes KR, Belager K, Murk W, Bracken MB. Antibiotic exposure by 6 months and asthma and allergy at 6 years: Findings in a cohort of 1,401 US children. Am J Epidemiol 2011; 173:310-318.

30. Marra F, Lynd L, Coombes M, et al. Does antibiotic exposure during infancy lead to development of asthma? A systematic review and metaanalysis. Chest 2006; 129:610-618.

31. Kummeling I, Thijs C, Stelma F, Huber M, van den Brandt PA, Dagnelie PC. Diphtheria, pertussis, poliomyelitis, tetanus, and Haemophilus influenzae type $b$ vaccinations and risk of eczema and recurrent wheeze in the first year of life: the KOALA Birth Cohort Study. Pediatrics 2007; 119:e367-373. 